\title{
PAPER ELECTROPHORESIS AS A QUANTITATIVE METHOD: THE STAINING OF SERUM LIPOPROTEINS
}

\author{
By WILliam P. JENCKS ${ }^{1}$ and E. L. DURRUM ${ }^{2}$ With THE technical assistance of \\ MERA R. JETTON \\ (From the Department of Pharmacology, Army Medical Service Graduate School, Walter \\ Reed Army Medical Center, Washington, D. C.)
}

(Submitted for publication March 21, 1955 ; accepted May 11, 1955)

Electrophoresis of serum on filter paper followed by staining ${ }^{3}$ of the lipoprotein fractions with lipid dyes is technically the simplest method for the separation and estimation of serum lipoproteins. A number of procedures for the staining of separated lipoproteins on paper with various lipid dyes have appeared (1-8), but the only comprehensive consideration of the quantitative aspects of dye binding by serum lipids on paper is the very careful study reported by Swahn (9), which was primarily concerned with the quantitative aspects of the staining of whole serum on paper with a preparation of the lipid dye Sudan black.

A critical study of some of the characteristics of the staining of electrophoretically separated lipoproteins on paper and a detailed procedure for a semi-quantitative empirical determination of serum lipoprotein distribution with the lipid dye oil red $\mathrm{O}$ are reported here.

\section{MATERIALS AND METHODS}

Electrophoretic separation of serum lipoprotein fractions was carried out on eight $2.9 \times 30.0 \mathrm{~cm}$. Whatman $3 \mathrm{MM}$ filter paper strips moistened with $0.05 \mu \mathrm{pH} 8.6$ diethyl barbiturate buffer in the cell previously described (10). A volume of $0.02 \mathrm{ml}$. of serum was applied with a micropipette to the apex of each paper strip, which previously had been thoroughly wet with buffer and allowed to drain in the closed cell for 15 minutes. A constant potential of 220 volts (about 14-17 m.a.) was applied for two hours, after which the strips were spread flat, pulled almost taut and dried in an oven at 110 to $120^{\circ}$ C. for 15 minutes. No significant differences in

\footnotetext{
1 Present address: Biochemical Research Laboratory, Massachusetts General Hospital, Fruit St., Boston, Mass.

2 Present address : Department of Pharmacology, Stanford University Medical School, Clay \& Webster Sts., San Francisco 15, California.

3 The use of the terms "stain" and "dye" is not meant to imply the existence of a chemical union between "dye" and lipid.
}

lipid dye uptake or distribution were found when the period of oven drying was varied from 10 to 40 minutes.

Oil red $O$ staining solution was prepared by adding 0.4 g. of solid dye (lot 15123, National Aniline Division, Allied Chemical and Dye Corp.) to a liter of 60 per cent ethanol $(\mathrm{V} / \mathrm{V})$, bringing the mixture to a boil in a flask fitted with a condenser to prevent loss of alcohol, and allowing the solution to cool overnight in a $30^{\circ} \mathrm{C}$. incubator with constant stirring by means of a magnetic stirrer. Omission of stirring resulted in the formation of a fine suspension of dye which was difficult to clarify. The solution (at about $33^{\circ}$ ) was filtered and kept in the incubator. When the same solution of dye was used for the staining of five groups of eight strips each over an eight-day period, the total amount of dye taken up by a given serum sample decreased by 25 per cent, but the relative amounts of dye bound by the alpha and beta lipoprotein fractions was the same at the end of the period as at the beginning.

Staining of strips was carried out for 18 hours at $30^{\circ} \mathrm{C}$. The strips were held in racks which were placed in 1 liter of staining solution in a closed container ("plastic sandwich boxes," American Thermos Bottle Co.). After removal from the staining solution the rack was immediately placed in a container filled with tap water at room temperature and rinsed with constant agitation until the alcohol was removed from the paper (about two minutes). The strips were then blotted and allowed to dry at room temperature. Although some fading of dye takes place on prolonged exposure of the dry strips to bright light, no significant difference in dye content was found between strips eluted immediately after staining and strips which had stood for a month without exposure to bright light.

Staining with Sudan black B (NZb 6; National Aniline Division, Allied Chemical and Dye Corp.) was carried out according to the directions of Swahn (9). Because of a tendency of this dye to develop a brownish discoloration on standing, Sudan black strips were eluted shortly after the staining procedure.

Elution of dye was carried out with a solution containing $125 \mathrm{ml}$. of glacial acetic acid diluted to $500 \mathrm{ml}$. with absolute ethanol (9). The stained strips were marked off into two $2.5 \mathrm{~cm}$. segments containing the alpha and beta lipoprotein bands, with the point of division of the two segments about $2 \mathrm{~mm}$. ahead of the sharply defined front of the beta band. Five $\mathrm{cm}$. segments were marked off from the protein free cathode side of the 
strips to serve as blanks. The segments were cut out, placed in $5.0 \mathrm{ml}$. of acetic acid-ethanol in stoppered tubes, and shaken at 2501.5 inch strokes per minute for two hours at room temperature. Elution was complete after this period of shaking as shown by the absence of any change in readings after a further two hours of shaking. The solutions were read with a Beckman model DU spectrophotometer at $520 \mathrm{~m} \mu$, which is at or close to the rather broad absorption maxima of all of the colored components in oil red $\mathrm{O}$ preparations. The concentration of oil red $\mathrm{O}$ has a linear relationship to optical density up to a reading of 1.3 in the Beckman instrument. Sudan black gives a linear response up to an optical density of 0.7 at $590 \mathrm{~m} \mu$ in the Coleman Junior spectrophotometer, and was measured in this instrument. The readings obtained on eluates from the $5 \mathrm{~cm}$. blank segments, were divided in half to correspond to the $2.5 \mathrm{~cm}$. segments, and were then subtracted from the values obtained for the alpha and beta bands. Optical densities obtained for the alpha lipoprotein segments with oil red $O$ were about double the blank values for most sera; the beta lipoprotein values were correspondingly higher. The data reported in this paper are in terms of optical density of the $5 \mathrm{ml}$. elution samples at $520 \mathrm{~m} \mu$ after subtraction of the blank values unless otherwise specified; no attempt was made to convert the results to actial quantities of dye bound because of the heterogeneity of the dye preparations.

Direct optical scanning of dry strips was carried out with the instrument previously described (11), using a $2 \times 23 \mathrm{~mm}$. slit and a $525 \mathrm{~m} \mu$ Bausch and Lomb first order interference filter with a tungsten light source. Paper was not "cleared" with mineral oil (12) or glycerol (13) because of the solubility of lipid dyes in the former and the appearance of artifacts due to difficulty in wetting protein bands with the latter. Because of the considerable background variation with consequent difficulties in selecting a true base line, the non-linearity of the relationship between dye concentration and optical density on paper $(12,14,15)$ and the ease of eluting dye from only two lipoprotein fractions, quantitative measurements were not attempted with the direct scanning procedure.

\section{RESULTS}

\section{Electrophoretic separation}

The separation of alpha and beta lipoprotein fractions by electrophoresis on filter paper under the conditions described has been discussed elsewhere (16). A clear separation of alpha and beta

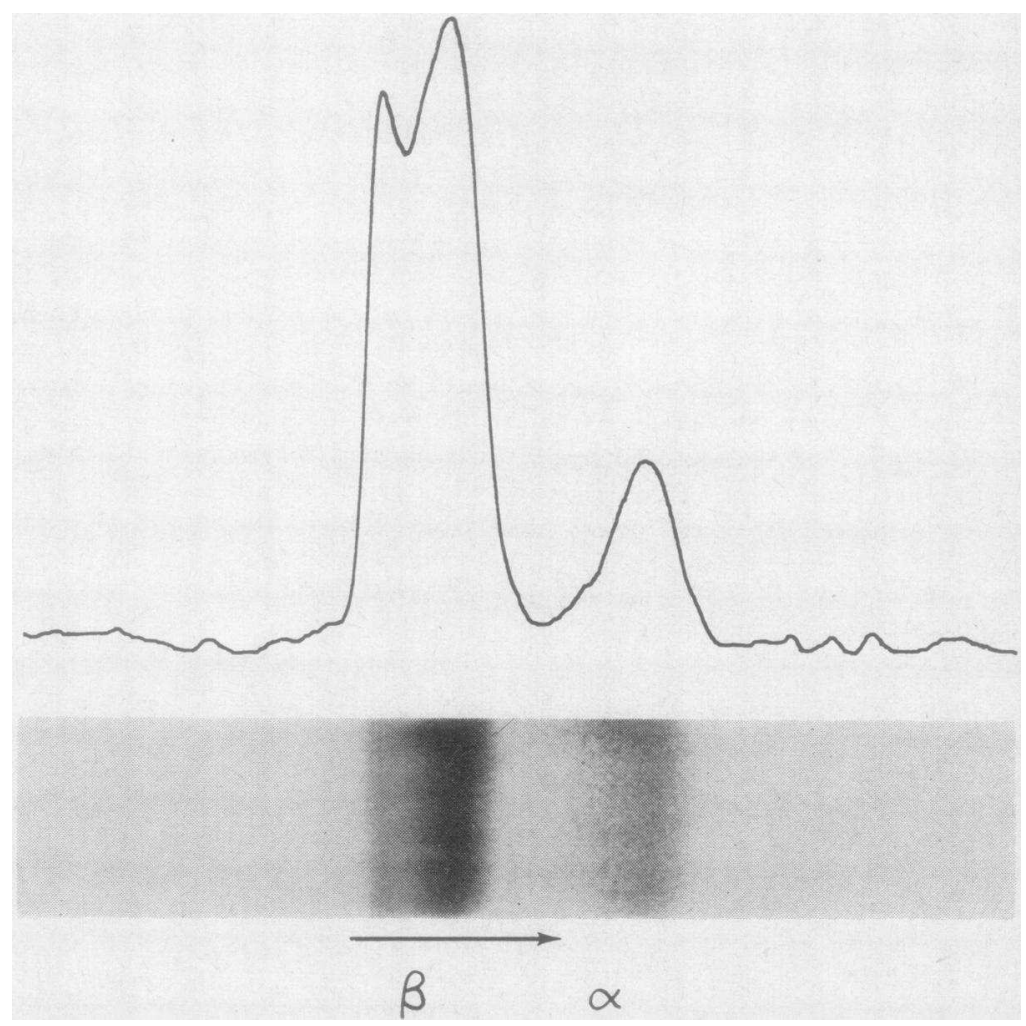

Fig. 1. Electrophoretically Separated Normal Serum on Paper Stained with Oil Red O and A Direct Photoelectric Scan Pattern of the Same Strip 


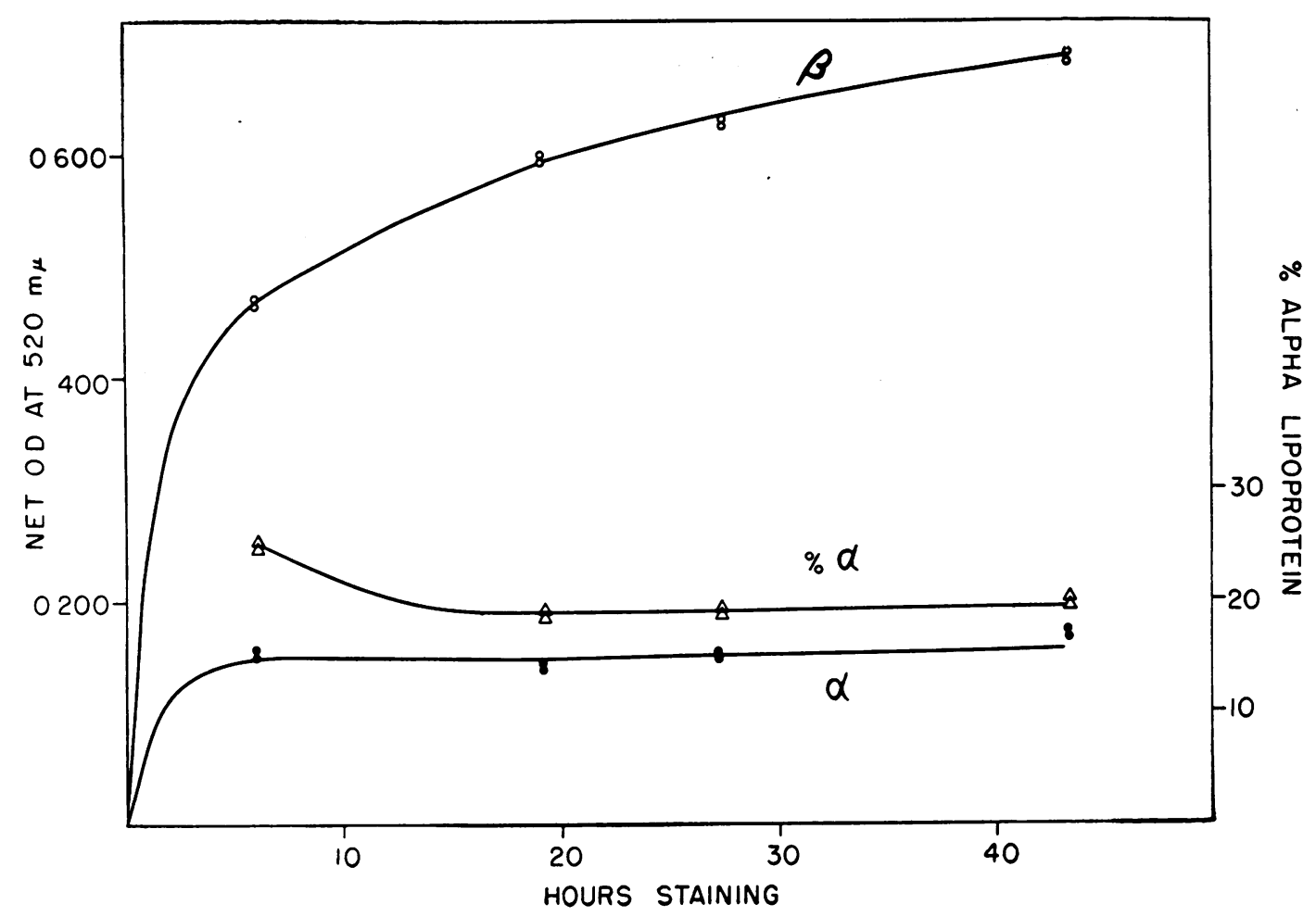

Fig. 2. Dye Uptake of Alpha and Beta Lipoprotein Fractions of Serum with Increasing Time in the Staining Solution

bands is uniformly obtained, and except for chylomicrons and beta lipoprotein adsorbed at the origin and certain abnormal "beta lipoproteins" of increased mobility, no evidence has been obtained for the presence of subfractions in practicably measurable amounts. The occurrence of significant amounts of "tailing" of alpha lipoprotein is unlikely in view of the linear dye uptake obtained on separation and staining of increasing amounts of this fraction (Figure 3). A typical stained strip obtained with normal serum, and a tracing of a direct optical scan pattern of the same strip are shown in Figure 1.

\section{Staining}

Figure 2 shows the relationship between the duration of staining and the amount of oil red $\mathrm{O}$ taken up by electrophoretically separated alpha and beta lipoprotein fractions from a saturated solution of dye in 60 per cent ethanol. Although some dye uptake continues up to at least 40 hours, most of the dye is taken up during the first 18hour period, the time ordinarily used for staining, and there is little or no change in the distribution of dye between the alpha and beta fractions after this time. Similar studies of the uptake of oil red $O$ from 55 per cent and 50 per cent ethanol and of Sudan black from 40 per cent ethanol have indicated that equilibrium is approached somewhat more slowly with these solvents.

The relationship between lipoprotein concentration and amount of dye bound is shown in Figure 3. A volume of 0.01 to $0.04 \mathrm{ml}$. aliquots of serum were electrophoretically separated and stained, and the dye was eluted from the alpha and beta lipoprotein fractions. Although the uptake of dye by alpha lipoprotein is linear with increasing lipoprotein concentration, there is a deviation from linearity with the more concentrated beta lipoprotein. As a result of this deviation the per cent of the total dye bound by the alpha lipoprotein fraction increased from 20.8 per cent at the lowest concentration to 23.7 per cent at the highest concentration of lipoproteins studied in this experiment. Since part of the alpha lipoprotein fraction, which shows no such deviation, is in the same area of the paper strip as the very concentrated albumin fraction, it appears unlikely 
that high concentrations of protein interfere with dye uptake or are responsible for the deviation from linearity observed with beta lipoprotein.

\section{Effect of the dye solvent on staining}

In theory, the uptake of lipid dyes by fats is supposed to be a process of physical solution, with the greater solubility of the dye in lipid than in solvent resulting in a high concentration of dye in the lipid $(17,18)$. A quantitative interpretation of this picture requires the existence of a two phase system of lipid and solvent between which dye would be distributed at equilibrium according to a distribution coefficient defined by the relative solubility of the dye in the two phases. Since the change in dye concentration in the solvent during the staining procedure is negligible because of the large volume of solution, the concentration of dye in the lipid should reach a constant value at equilibrium. Provided that none of the lipid phase is dissolved in the dye solvent during the equilibration period, the amount of dye found in the lipid phase would then be a measure of the amount of lipid present.

If this picture is correct, it follows that reexposure of stained lipid to solvent without dye should result in the removal of dye from the lipid until a new equilibrium is set up. Also, since the amount of dye taken up by a given amount of lipid should be directly proportional to the concentration of dye in the solvent, there should be little variation in the total amount of dye taken up by a given amount of lipid when stained in different solutions of dye at approximately the same concentration.

Several lines of evidence indicate that this hypothesis cannot be applied without reservations to the staining of lipid on paper by lipid dyes. The heterogeneity of both lipids and dyes and the large variations in dye uptake obtained for the same amount of lipid with dye solutions of almost identical concentration are described below; an experiment to study the solubility of lipid in the dye solvent is described here.

Strips on which $0.02 \mathrm{ml}$. of serum had been separated were allowed to stand for 18 hours in 60 per cent ethanol at room temperature and at $30^{\circ} \mathrm{C}$. and were then rinsed in water, dried, and stained in a saturated solution of dye in 60 per
TABLE I

Solubility of serum lipids in 60 per cent ethanol in the absence of dye*

\begin{tabular}{lcc}
\hline \hline \multicolumn{1}{c}{ Pre-treatment } & $\begin{array}{c}\text { Net total } \\
\text { dye uptake } \\
(\text { O.D. } 520 \mathrm{m \mu} / 5 \mathrm{ml} .)\end{array}$ & $\begin{array}{c}\text { Alpha } \\
\text { lipoprotein } \\
\text { dye uptake } \\
\text { (\% of total })\end{array}$ \\
\hline Control & 0.803 & 22.2 \\
& 0.791 & 21.1 \\
$60 \%$ ethanol at & 0.570 & 16.1 \\
room temperature & 0.590 & 15.1 \\
$60 \%$ ethanol at & 0.521 & 12.9 \\
$30^{\circ} \mathrm{C}$. & 0.532 & 14.1
\end{tabular}

* Identical strips were placed in 60 per cent ethanol at room temperature or at $30^{\circ} \mathrm{C}$. for 18 hours, rinsed in water, and stained. Control strips were not placed in ethanol until stained.

cent ethanol. Identical control strips were carried through the same procedure except for the preliminary soaking in alcohol. The uptake of dye by the alpha and beta lipoprotein fractions on strips treated in this manner is shown in Table I. The total dye uptake is reduced 25 to 35 per cent by the preliminary soaking, and this decrease is greater for the alpha than for the beta fraction, thus giving rise to a different distribution of dye between the two fractions. In similar experiments a 27 per cent decrease in dye uptake was found after preliminary washing in diethylene glycol and a 22 per cent decrease after 50 per cent ethanol (in the latter case followed by staining in 50 per cent rather than 60 per cent ethanol).

Although this type of experiment provides no information as to the solubility of serum lipids in 60 per cent alcohol that is saturated with dye, it does indicate that some of the lipids are soluble in the dye solvent in the absence of dye, but are not dissolved in the presence of dye. The losses obtained with the preliminary washing cannot be due simply to an increased length of exposure to 60 per cent ethanol as compared to the control strips, since prolonged exposure to the same solvent in the presence of dye results in an increase rather than a decrease in dye uptake (Figure 2).

In an attempt to find a staining system in which lipid would not be dissolved by the solvent, several aqueous media were tested in which dye was held in solution or suspension by gelatin (19), gum arabic, saponin, polyoxyethylene sorbitan 


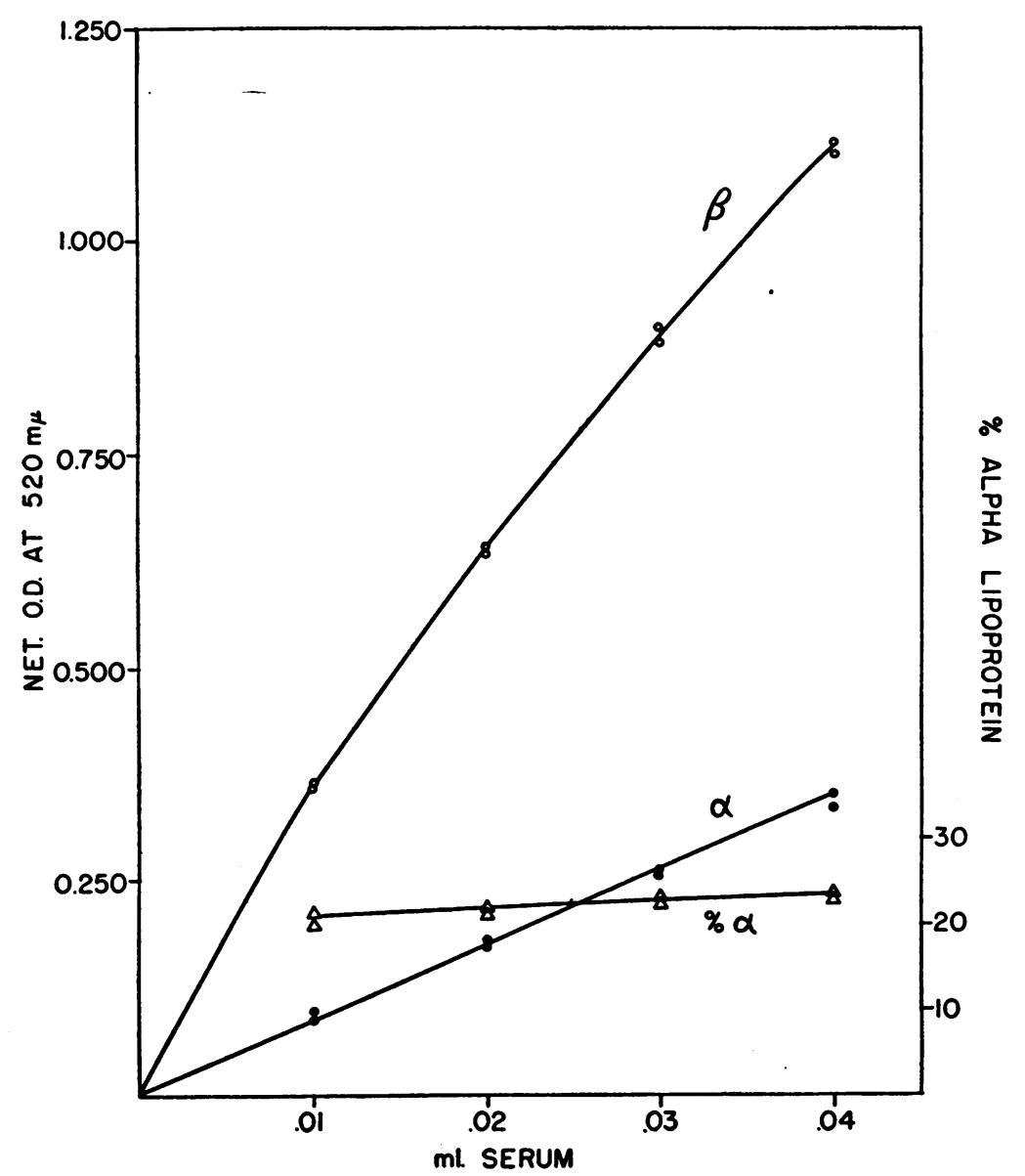

Fig. 3. Dye Uptake of InCreasing Amounts of Electrophoretically Separated Serum Stained with Oil Red O

monolaurate (Tween $20^{4}$ ) or polyoxyethylene lauryl alcohol (Brij $35^{4}$ ). Many preparations of this type caused artifacts by precipitation of dye on protein fractions which did not contain lipid. Saturated solutions of oil red $\mathrm{O}$ in acetone added to an equal volume of 1 per cent gelatin in 1 per cent acetic acid and allowed to stand at $37^{\circ}$ overnight (19) produced good lipid stains, but led to precipitation of dye on the paper resulting in too high a background for practical use. Clear stable solutions of oil red $\mathrm{O}$ could be prepared in 0.1 per cent Tween 20 or Brij 35 by adding 0.1 to 1.0 $\mathrm{ml}$. of a saturated solution of dye in dioxane to $100 \mathrm{ml}$. of solution; fairly good stains could be obtained from these preparations at $57^{\circ}$, especially with $\mathrm{Brij}$, but it was found that aqueous solutions

4 We wish to thank the Atlas Powder Company for samples of these materials. of these detergents have the same disadvantage as 60 per cent ethanol in that they wash out a fraction of the serum lipids from the paper strip.

\section{Composition of the staining solution}

Commercially available oil red $\mathrm{O}$ consists of at least four chromatographically distinct colored components. In Figure 4 are shown tracings of reversed phase chromatograms of the crude dye, the dye present in the staining solution and the dye which actually stains lipid (obtained by elution of a stained lipoprotein band). The separations were obtained in 16 hours at room temperature with Whatman $3 \mathrm{MM}$ paper which had been dipped into a 30 per cent solution of mineral oil in ether and allowed to dry, using water saturated n-butanol as developing solvent. The principal component in each case is the slowest mov- 


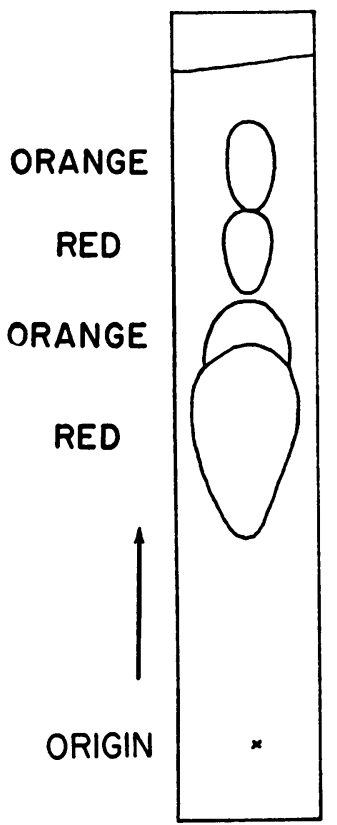

A

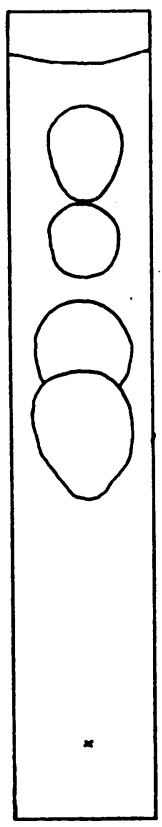

B

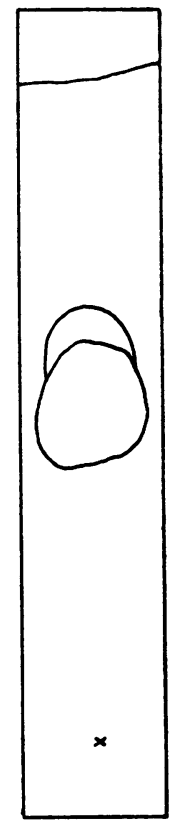

C
Fig. 4. Tracings of Reverse Phase Chromatograms OF OII RED O

A. Crude Dye

B. Dye from Solutton Used for Staining

C. Dye Eluted from Stained Beta Lipoprotein Band

ing red band, and this is the principal fraction which actually stains the lipoprotein as shown by chromatography of the eluted material. A slightly faster moving orange component is present in greater concentration in the staining solution than in the original dye preparation because of the use of a large excess of solid dye for saturation of the staining solution.

Attempts to stain lipoproteins with purified preparations containing less of the orange component were uniformly unsuccessful. When chromatographically homogeneous preparations of the main red component, prepared by fractional precipitation from dioxane-water or by chromatography on alumina, were used for staining only very dilute dye solutions and faint stains were obtained; the same results were obtained with staining solutions which were saturated with a minimum amount of the solid dye so that they contained little of the minor components. No success was achieved with attempts to substitute non-ionic detergents for the orange component, which might be acting by solubilizing or stabilizing the red fraction. It would appear, then, that even though the red dye is the major staining component, the presence of other fractions from the crude preparation is necessary for satisfactory staining.

Chromatograms of Sudan black B on circular filter paper, developed with a mixture of two parts of 25 per cent acetic acid in ethanol to one part of water, indicated the presence of at least four components in this preparation of this dye also, as previously found by McDonald (20).

It might be expected that different lots of oil red $\mathrm{O}$, containing different amounts of the minor dye components, might stain differently. This was found to be the case with the four different lots of dye tested as shown in Table II. The absolute amount of dye uptake varied up to two-fold with different preparations, and the fraction of dye taken up by alpha lipoprotein varied from 20.8 per cent to 26.3 per cent. It is of interest that in two staining solutions which gave dye uptakes differing more than 100 per cent, the concentration of dye in the staining solution differed by less than 1 per cent.

\section{Rinsing}

In order to reduce the blank value due to dye in lipid free portions of the filter paper it is desirable to rinse the stained strips to remove residual dye solution trapped in the paper fibers; if a concentrated dye solution is used for staining, rinsing becomes absolutely necessary if a reasonable pattern to background ratio is to be achieved. A necessary requirement of any rinsing procedure, however, is that it remove only background dye, not any of the dye bound to lipoprotein.

TABLE II

Oil red $O$ uptake of separated lipoprotein fractions using different lots of dye

\begin{tabular}{cccc}
\hline \hline $\begin{array}{c}\text { Lot } \\
\text { number }\end{array}$ & $\begin{array}{c}\text { Concentration } \\
\text { of staining } \\
\text { solution } \\
(O . D .520 \mathrm{m \mu})\end{array}$ & $\begin{array}{c}\text { Net total } \\
\text { dye uptake } \\
\text { by lipoprotein } \\
(O . D .520 \text { m } / 5 \text { ml. })\end{array}$ & $\begin{array}{c}\text { Alpha } \\
\text { lipoprotein } \\
\text { dye uptake } \\
\text { (\% of total) }\end{array}$ \\
\hline 12670 & 3.108 & 1.068 & 24.3 \\
14714 & 3.432 & 1.063 & 24.6 \\
15123 & 3.408 & 1.114 & 22.4 \\
& & 1.133 & 22.3 \\
15448 & 3.402 & 0.630 & 21.9 \\
& & 0.586 & 20.8 \\
& & 1.354 & 26.3 \\
\end{tabular}




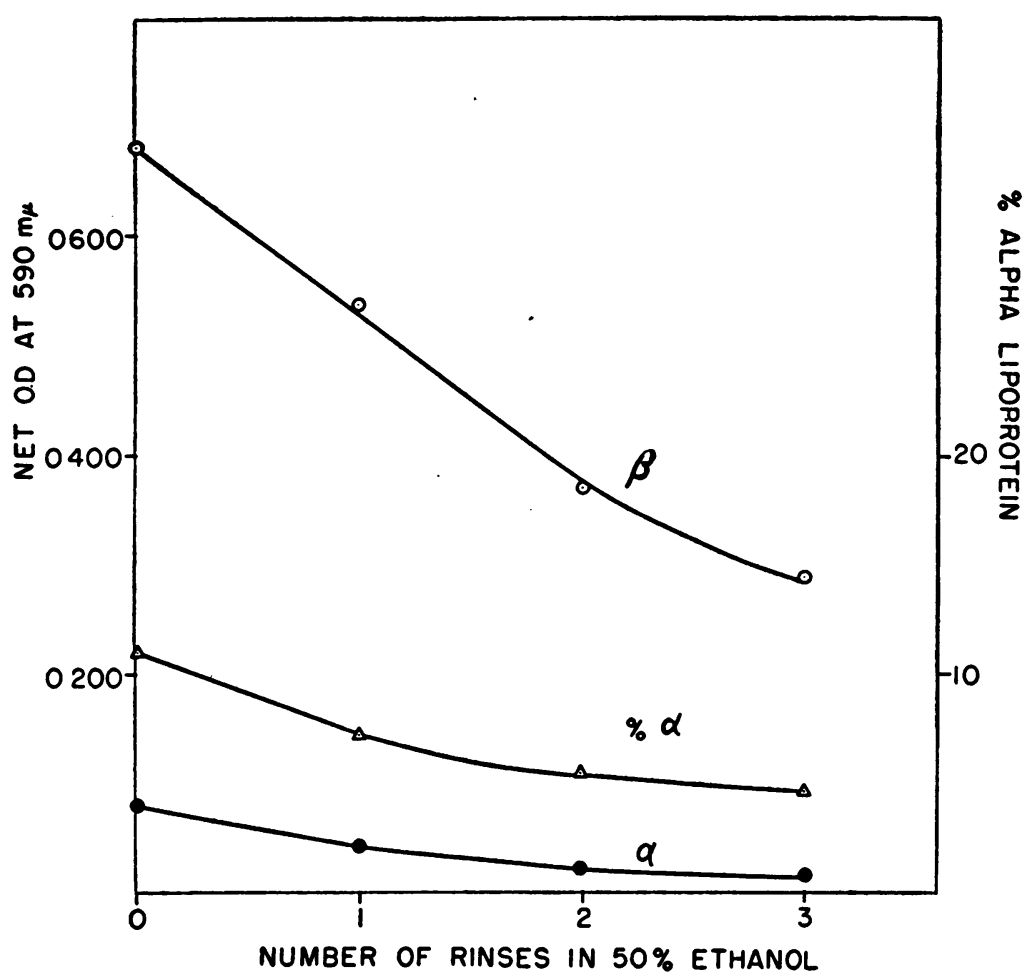

Fig. 5. Loss of Dye from Electrophoretically Separated Serum Stained with Sudan Black B on Rinsing in 50 Per Cent Ethanol

The recovery of dye from stained separated serum lipoproteins after rinsing in 50 per cent ethanol is shown in Figure 5. Serum was electrophoretically separated on Whatman No. 1 paper strips, stained with Sudan black B, and eluted after one, two, and three 15-minute rinses as described by Swahn (9). Corresponding background values were subtracted from each lipoprotein value. There is a considerable loss of dye in excess of background from both lipoprotein fractions, and the proportionally greater loss from the less concentrated alpha fraction results in progressively lower values for the portion of the total dye bound by this fraction.

Loss of dye from stained lipoprotein fractions during alcohol rinsing has also been observed with Whatman $3 \mathrm{MM}$ paper and with oil red $\mathrm{O}$ dye. Loss of dye during rinsing would indeed be expected from the two phase partition theory of staining, since a new equilibrium of dye distribution between solvent and lipid should be set up with each rinse.
In order to avoid the use of rinsing solutions in which dye is soluble, oil red $O$ stained strips are rinsed briefly in water with agitation. This serves to wash out some of the trapped staining solution before the dye can precipitate on the paper fibers and thus decreases the background by some 20 to 30 per cent without removing an appreciable amount of dye from the lipoprotein bands (Table III).

TABLE III

Effect of water rinsing on the amount of dye recovered from separated alpha and beta lipoprotein fractions stained with oil red $O^{*}$

\begin{tabular}{|c|c|c|c|}
\hline Treatment & $\begin{array}{c}\text { Dye } / 2.5 \mathrm{~cm} . \\
\text { background } \\
(O . D .520 \mathrm{m \mu} / \\
5 \mathrm{mb} .)\end{array}$ & $\begin{array}{c}\text { Net total } \\
\text { dye uptake } \\
\text { by lipoprotein } \\
(O . D .520 \mathrm{m \mu} / \\
5 \mathrm{ml} .)\end{array}$ & $\begin{array}{l}\text { Alpha } \\
\text { lipoprotein } \\
\text { dye uptake } \\
\text { (\% of total) }\end{array}$ \\
\hline Control & $\begin{array}{l}0.261 \\
0.268\end{array}$ & $\begin{array}{l}0.771 \\
0.789\end{array}$ & $\begin{array}{l}23.1 \\
22.2\end{array}$ \\
\hline Rinsed & $\begin{array}{l}0.201 \\
0.204\end{array}$ & $\begin{array}{l}0.803 \\
0.791\end{array}$ & $\begin{array}{l}22.2 \\
21.2\end{array}$ \\
\hline
\end{tabular}

* Control strips were blotted immediately after removal from the staining solution. 


\section{The chemical significance of lipid staining}

Studies of the specificity of lipid staining in the histological literature have led to the conclusion that such dyes as oil red $\mathrm{O}$ and the Sudan group are taken up by those phospholipids, neutral fats, and cholesterol esters which are in the liquid state at the temperature of staining and which are not soluble in the dye solvent $(18,21,22)$. There is some evidence that different lipids present in a mixture may influence each other's dye uptakes (22). Swahn (9) has shown that the uptake of a preparation of Sudan black by whole serum on filter paper is correlated with the total lipid content of serum; he suggests that the solid lipids such as cholesterol which ordinarily do not take up dye will be stained in serum because of the presence of liquid lipids in which they may be dissolved.

The results of an experiment to test the dye uptake of mixtures of cholesterol and liquid triolein are shown in Table IV. Increasing amounts of cholesterol were added to a solution of triolein in chloroform and the mixtures were applied to paper strips, dried, stained with oil red $\mathrm{O}$, and eluted. Under these conditions cholesterol takes up a negligible quantity of dye and this uptake is not significantly increased by the presence of triolein.

When isolated lipids dissolved in chloroform were applied to paper, dried and stained, it was found that oil red $O$ and Sudan black in 60 per cent ethanol stain triglycerides and lecithin, but that little or no color is obtained with cholesterol, oleic acid, palmitic acid, or ethyl esters of saturated fatty acids with eight to sixteen carbon atoms. Tristearin (m.p. $55^{\circ}$ ), is stained at $30^{\circ}$, in conflict with the theory that only liquid lipids take up dye.

It is likely that phospholipids in serum also are stained with oil red $\mathrm{O}$ since after washing serum

TABLE IV

Dye uptake by mixtures of triolein and cholesterol

\begin{tabular}{ccc}
\hline $\begin{array}{c}\text { Triolein } \\
\mu g .\end{array}$ & $\begin{array}{c}\text { Cholesterol } \\
\mu \mathrm{g} .\end{array}$ & $\begin{array}{c}\text { Net dye } \\
\text { uptake }\end{array}$ \\
\hline 125 & 0 & $($ O.D. $520 \mathrm{m \mu} / 5 \mathrm{ml})$. \\
125 & 31.3 & 0.243 \\
125 & 62.5 & 0.260 \\
125 & 125 & 0.279 \\
0 & 125 & 0.290 \\
& & 0.023 \\
\hline
\end{tabular}

strips with acetone at $50^{\circ}$, which is supposed to dissolve all lipids except phospholipids (23), dye is taken up by alpha and beta lipoproteins of normal serum in approximately equal amounts, the total dye uptake amounting to about one-fourth of that in unwashed strips. No appreciable amount of dye is taken up after extraction by hot 2-1 chloroform-methanol.

\section{Reproducibility}

In order to obtain any satisfactory reproducibility of staining with lipid dyes it was found necessary to control carefully the temperature during the staining procedure and the composition of the staining solution by close attention to detail in its preparation. The results of a study of the reproducibility of the method as described, under conditions of routine use, are shown in Table V. Analyses were carried out in duplicate on four different normal and abnormal sera which were electrophoretically separated, stained, and eluted on five different occasions over a period of ten days, using a different preparation of dye for each run.

Under these conditions the distribution of dye between the two lipoprotein fractions, as measured by the per cent of the total dye uptake found in the alpha fraction, shows a maximum range of variation of 4.2 per cent ( 32.6 to 36.8 per cent) in any two individual determinations on the same serum; there is no overlap of the values for the four different sera studied. The total dye uptake shows an almost two-fold range of variation between the highest and lowest values for a single serum in spite of the fact that the concentration of dye in the different staining solutions varied by no more than 6 per cent as shown by measurement of optical density at $520 \mathrm{~m} \mu$; there was no relationship between the amount of dye uptake and the concentration of dye in the staining solution. However, if serum P II is arbitrarily selected as a standard with a total dye uptake of 100 units, and the other sera in each run are compared to this standard, the results are more satisfactory with a maximum range of variation of 10 per cent between any two values for the same serum; again there is no overlap of the values for the different sera.

It should be noted that if comparisons are made of the results from duplicate analyses, considerably 
TABLE $\mathbf{V}$

Reproducibility of lipoprotein separation and staining of four different sera on five occasions over a 10-day period

\begin{tabular}{|c|c|c|c|c|c|c|c|}
\hline \multirow{2}{*}{$\begin{array}{l}\text { Serum } \\
\text { P II* }\end{array}$} & \multirow{2}{*}{$\begin{array}{c}\text { Exp. No. } \\
1 \\
2 \\
3 \\
4 \\
5\end{array}$} & \multicolumn{2}{|c|}{$\begin{array}{l}\text { \% Alpha } \\
\text { lipoprotein }\end{array}$} & \multicolumn{2}{|c|}{$\begin{array}{c}\text { Net total } \\
\text { dye uptake } \\
(O . D .520 \mathrm{m \mu} / 5 \mathrm{ml} .)\end{array}$} & \multicolumn{2}{|c|}{$\begin{array}{c}\text { Total dye } \\
\text { uptake using } \\
\text { P II as standard } \\
\text { (arbitrary units) }\end{array}$} \\
\hline & & $\begin{array}{l}22.6 \\
22.1 \\
19.2 \\
20.6 \\
21.0\end{array}$ & $\begin{array}{l}22.7 \\
21.8 \\
19.8 \\
20.3 \\
21.7\end{array}$ & $\begin{array}{l}0.875 \\
0.742 \\
0.665 \\
0.569 \\
0.708\end{array}$ & $\begin{array}{l}0.869 \\
0.736 \\
0.660 \\
0.575 \\
0.716\end{array}$ & $\begin{array}{l}100 \\
100 \\
100 \\
100 \\
100\end{array}$ & $\begin{array}{r}99 \\
99 \\
99 \\
101 \\
101\end{array}$ \\
\hline & Average & \multicolumn{2}{|c|}{21.2} & \multicolumn{2}{|c|}{0.711} & \multicolumn{2}{|c|}{100} \\
\hline \multirow[t]{2}{*}{ S 1601} & $\begin{array}{l}1 \\
2 \\
3 \\
4 \\
5\end{array}$ & $\begin{array}{l}31.1 \\
30.5 \\
28.9 \\
28.1 \\
28.5\end{array}$ & $\begin{array}{l}31.6 \\
29.7 \\
29.6 \\
27.6 \\
28.0\end{array}$ & $\begin{array}{l}0.999 \\
0.859 \\
0.771 \\
0.648 \\
0.808\end{array}$ & $\begin{array}{l}1.000 \\
0.878 \\
0.774 \\
0.648 \\
0.839\end{array}$ & $\begin{array}{l}114 \\
117 \\
116 \\
114 \\
114\end{array}$ & $\begin{array}{l}114 \\
118 \\
116 \\
114 \\
118\end{array}$ \\
\hline & Average & \multicolumn{2}{|c|}{29.4} & \multicolumn{2}{|c|}{0.822} & \multicolumn{2}{|c|}{115} \\
\hline \multirow[t]{2}{*}{ S 1605} & $\begin{array}{l}1 \\
2 \\
3 \\
4 \\
5\end{array}$ & $\begin{array}{l}35.9 \\
35.9 \\
34.4 \\
33.8 \\
32.8\end{array}$ & $\begin{array}{l}36.8 \\
36.5 \\
35.4 \\
32.6 \\
32.9\end{array}$ & $\begin{array}{l}0.788 \\
0.696 \\
0.608 \\
0.492 \\
0.634\end{array}$ & $\begin{array}{l}0.779 \\
0.698 \\
0.597 \\
0.482 \\
0.638\end{array}$ & $\begin{array}{l}90 \\
94 \\
91 \\
86 \\
89\end{array}$ & $\begin{array}{l}89 \\
94 \\
90 \\
84 \\
90\end{array}$ \\
\hline & Average & \multicolumn{2}{|c|}{34.7} & \multicolumn{2}{|c|}{0.641} & \multicolumn{2}{|c|}{90} \\
\hline \multirow[t]{3}{*}{ S 1608} & $\begin{array}{l}1 \\
2 \\
3 \\
4 \\
5\end{array}$ & $\begin{array}{l}12.4 \\
13.2 \\
11.5 \\
11.5 \\
11.0\end{array}$ & $\begin{array}{l}13.7 \\
12.9 \\
11.4 \\
11.3 \\
10.9\end{array}$ & $\begin{array}{l}1.128 \\
0.991 \\
0.925 \\
0.785 \\
0.976\end{array}$ & $\begin{array}{l}1.106 \\
1.006 \\
0.907 \\
0.768 \\
0.975\end{array}$ & $\begin{array}{l}129 \\
134 \\
139 \\
138 \\
138\end{array}$ & $\begin{array}{l}126 \\
135 \\
136 \\
135 \\
137\end{array}$ \\
\hline & Average & \multicolumn{2}{|c|}{12.0} & \multicolumn{2}{|c|}{0.957} & \multicolumn{2}{|c|}{135} \\
\hline & $\begin{array}{c}\text { Exp. No. } \\
\begin{array}{c}1 \\
2 \\
3 \\
4 \\
5\end{array}\end{array}$ & $\begin{array}{c}\text { Conc } \\
\text { stain } \\
(0.1\end{array}$ & $\begin{array}{l}\text { ion of } \\
\text { lution } \\
m \mu) \\
\text { ma) }\end{array}$ & & & & \\
\hline
\end{tabular}

* Pooled serum from 10 blood donors.

less variation is found. The maximum differences between the results for any two analyses made on the same serum at the same time are 1.3 per cent (12.4 to 13.7 per cent) for the per cent alpha lipoprotein and 0.031 (0.808 to 0.839$)$ optical density units per $5 \mathrm{ml}$. for the total dye uptake. Since other experiments have shown that strips which are run together but stained separately show a considerable range of variation, it may be inferred that the variations in dye uptake are due to differences in staining with different dye solutions rather than to differences in the electrophoretic separation.

\section{DISCUSSION}

The staining of electrophoretically separated lipoproteins by oil red $\mathrm{O}$ has the following characteristics; some of these points apply to other staining procedures as well:

1) The increase in dye uptake with increasing lipoprotein concentration is not strictly linear. The resulting variation in the distribution of dye between alpha and beta lipoproteins is, however, no greater than the range of variation of individual determinations on the same serum found in the reproducibility study; thus there will be no appreciable error due to non-linearity in an indi- 
vidual determination, but there will be a systematic error in the analysis of large numbers of samples tending towards erroneously low values for beta lipoproteins in high concentration.

2) The solvent for the staining solution, 60 per cent ethanol, dissolves a portion of the lipid from serum lipoproteins in the absence of dye. Whether this occurs in the presence of dye is not known, but it appears likely that there is also a loss of lipid during the ordinary staining procedure. This is not unexpected in view of the known solubility of lipids in alcohol-water solutions under the conditions of histological staining (21). Staining solutions prepared with lower concentrations of alcohol or other solvents have not proved satisfactory in our hands, and indeed there is no reason to believe that other solvents will not dissolve lipid also if they are sufficiently hydrophobic to dissolve the lipid dye. It is therefore necessary to consider that a staining procedure of this type measures only lipid which is insoluble in the dye solvent in the presence of dye.

3) The quantitative chemical significance of the uptake of oil red $\mathrm{O}$ by separated lipoproteins is not known. It is possible, by analogy with the staining of whole serum by Sudan black, that dye uptake is correlated with total lipid content of these fractions, but without extensive further investigation of this problem there appears to be no justification for the use of specific chemical terms to express the results of dye binding analysis of separated lipoproteins; the results are best expressed in arbitrary units of dye binding, or as a ratio of dye bound by different fractions.

4) The commercial preparations of oil red $O$ and Sudan black which were examined contained at least four chromatographically distinct colored components. In the case of oil red $\mathrm{O}$ at least two components are necessary for satisfactory staining, although the major red component accounts for the majority of the dye actually taken up by lipid. More satisfactory staining with the use of dye mixtures has also been reported with the Sudan dyes in the histological staining of lipids (24). It is quite likely that variations in the proportion of these components in different lots of dye account for the variations in dye uptakes found with different lots. Cain (18) has reported that different preparations of Sudan black exhibit even greater variability in staining ability.
Although the reproducibility of the oil red $\mathrm{O}$ method is such that comparisons may be made among sera analyzed with the same lot of dye, it is necessary with different lots of dye to analyze control sera at the same time and under the same conditions to determine normal values. There does not appear to be a valid basis at present for the direct comparison of the results of different laboratories using lipid staining, or for the direct comparison of lipid staining procedures with other methods for measuring lipoproteins.

5) The reproducibility of the distribution of dye between alpha and beta lipoprotein fractions under the conditions described here is probably adequate for most purposes, but the uncorrected total dye uptake shows too much variability on different analyses to be of use as an absolute measure of lipid concentration. However, if a standard serum with a known lipid content determined by other methods is run at the same time as the sera being analyzed, satisfactory values for total dye uptake may be obtained. A known quantity of a stainable lipid could probably also be used as a standard, although the dye uptakes obtained should not be translated directly into terms of lipid concentration because of the uncertainty regarding the specific dye uptakes of different lipids.

6) In our hands the use of 50 per cent ethanol for rinsing of stained separated lipoproteins results in loss of dye from the stained lipoprotein fractions. This is in contrast to the results obtained on rinsing dye from whole serum applied in a spot to dry paper and stained, in which we have confirmed Swahn's observation that little or no dye is lost during rinsing (25). The most obvious difference between the situation with whole serum and separated lipoprotein bands is that the latter are spread over a considerable area of paper and are thoroughly exposed to the rinsing solution, while the former may be protected from loss of dye by incomplete equilibration between dye and rinsing solution. It is also possible that different results may be obtained with different dye preparations or filter papers, and in fact variations in the stoichiometry of dye binding with the use of different papers have been reported (9).

If no rinse is used, or only a water rinse, as described here, most of the background stain on the filter paper cannot be removed. This limits the 
selection of dyes that may be used for the staining procedure to those dyes which will give a good stain in a reasonable period of time from a dilute solution; more concentrated dye solutions result in too high a background. Oil red $O$ is a quite satisfactory dye in this respect, giving a comparatively high pattern to background ratio without alcohol rinsing.

It is apparent that the estimation of serum lipoproteins by staining with lipid dyes is not as simple a method as it might at first appear. Before even semi-quantitative validity can be ascribed to the results it is necessary to examine the technique in question with regard to the characteristics noted above. Nevertheless, for the semi-quantitative estimation of these lipoproteins, the staining procedure has the advantages of simplicity, ease of analysis of large numbers of samples, and provision of information as to the mobility and shape of the lipoprotein bands which are not obtained with other methods.

\section{SUMMARY}

1. A method is described for the semi-quantitative estimation of serum lipoprotein distribution by means of electrophoresis on filter paper followed by staining of the separated alpha and beta lipoprotein bands with the lipid dye oil red $O$.

2. This procedure has the following characteristics, some of which apply to other lipid staining procedures as well :

a. Twenty-five to thirty-five per cent of the lipid stained with a solution of dye in 60 per cent ethanol is soluble in 60 per cent ethanol in the absence of dye.

b. There is a deviation from linearity in the relationship between beta lipoprotein concentration and amount of dye bound; this is not of sufficient magnitude to cause a significant error in an individual determination.

c. No dye is lost from lipoprotein on rinsing the stained strips in water; a considerable loss of dye results from rinsing oil red $O$ or Sudan black stained strips in 50 per cent ethanol.

d. The method gives results in terms of dye uptake by lipid insoluble in the staining solution which cannot at this time be directly translated into chemical units. e. With use of different preparations of a single lot of dye the repeated determination of the lipoprotein distribution of four sera on five occasions shows satisfactory reproducibility; the reproducibility of total dye uptake is not satisfactory without use of a standard with each determination.

f. Commercial dye preparations contain at least four chromatographically distinct colored components; at least two of these are necessary for satisfactory staining. Variations in the composition of different lots of dye result in different staining characteristics of different lots.

3. If used with suitable controls and attention to the details of the procedure, the method described is suitable for the empirical measurement of the distribution and electrophoretic behavior of serum lipoproteins.

\section{REFERENCES}

1. Fasoli, A., Electrophoresis of serum lipoproteins on filter-paper. Lancet, 1952, 1, 106.

2. Kunkel, H. G., and Slater, R. J., Lipoprotein patterns of serum obtained by zone electrophoresis. J. Clin. Invest., 1952, 31, 677.

3. Durrum, E. L., Paul, M. H., and Smith, E. R. B., Lipid detection in paper electrophoresis. Science, 1952, 116, 428.

4. Rosenberg, I. N., Serum lipids studied by electrophoresis on paper. Proc. Soc. Exper. Biol. \& Med., 1952, 80, 751.

5. Gross, Ph., and Weicker, H., Die Bedeutung des Lipoidelektrophorese-diagrammes. Klin. Wchnschr., 1954, 32, 509.

6. Gottfried, S. P., Pope, R. H., Friedman, N. H., and DiMauro, S., A simple method for the quantitative determination of alpha and beta lipoproteins in serum by paper electrophoresis. J. Lab. \& Clin. Med., 1954, 44, 651.

7. McDonald, H. J., and Marbach, E. P., Improved detection of lipoproteins in human sera. Abstracts of Papers Presented at the 126th Meeting of the American Chemical Society, Sept. 12-17, 1954, p. 85C.

8. Wunderly, Ch., and Piller, S., Die Färbung der im Blutserum enthaltenen Proteine, Lipoide und Kohlenhydrate nach Papier-Electrophorese. Eine chemische Trias. Klin. Wchnschr., 1954, 32, 425.

9. Swahn, B., Studies on blood lipids. Scandinav. J. Clin. \& Lab. Invest., 1953, 5, suppl. 9.

10. Williams, F. G., Jr., Pickels, E. G., and Durrum, E. L., Improved hanging strip paper electrophoresis technique. Science, 1955, $121,829$.

11. Durrum, E. L., and Gilford, S. R., Recording integrating photoelectric and radioactive scanner for paper electrophoresis and chromatography. Rev. Scient. Instruments, 1955, 26, 51. 
12. Jencks, W. P., Jetton, M. R., and Durrum, E. L., Paper electrophoresis as a quantitative method. Serum proteins. Biochem. J., 1955, 60, 205.

13. Antonini, F. M., Piva, G., Salvini, L., and Sordi, A., Lipoprotein ed eparina nel quadro umorale della chemiopatogenesi dell aterosclerosi. Gior. di Gerontologia, 1953, suppl. 1.

14. Os, G. A. J. van, Critische beschouwing over de quantitatieve bepaling van de eiwitfracties bij papierelectrophorese. Chem. Weekblad, 1953, 49, 242.

15. Crook, E. M., Harris, H., Hassan, F., and Warren, F. L., Continuous direct photometry of dyed materials in filter paper with special reference to the estimation of proteins separated by electrophoresis. Biochem. J., 1954, 56, 434.

16. Langan, T. A., Durrum, E. L., and Jencks, W. P., Paper electrophoresis as a quantitative method: Measurement of alpha and beta lipoprotein cholesterol. J. Clin. Invest., 1955, 34, 1427.

17. I.illie, R. D., Histopathologic Technic and Practical Histochemistry. New York, Blakiston Co., 1954.
18. Cain, A. J., The histochemistry of lipoids in animals. Biol. Rev. Cambridge Philos. Soc., 1950, 25, 73.

19. Govan, A. D. T., Fat-staining by Sudan dyes suspended in watery media. J. Path. \& Bact., 1944, 56, 262.

20. McDonald, H. J., Personal communication.

21. Lillie, R. D., and Ashburn, L. L., Supersaturated solutions of fat stains in dilute isopropanol for demonstration of acute fatty degenerations not shown by Herxheimer technic. Arch. Path., 1943, 36, 432.

22. Kaufmann, C., and Lehmann, E., Sind die in der histologischen Technik gebräuchlichen Fettdifferenzierungsmethoden spezifisch? Virchows Arch. f. path. Anat., 1926, 261, 623.

23. Menschik, Z., Nile blue histochemical method for phospholipids. Stain Technol., 1953, 28, 13.

24. Kay, W. W., and Whitehead, R., The role of impurities and mixtures of isomers in the staining of fat by commercial Sudans. J. Path. \& Bact., 1941, 53, 279.

25. Unpublished observations. 